\title{
Deactivation Retards Recovery from Inactivation in Shaker $\mathrm{K}^{+}$Channels
}

\author{
Chung-Chin Kuo \\ Department of Physiology, National Taiwan University College of Medicine, and Department of Neurology, National \\ Taiwan University Hospital, Taipei 100, Taiwan, Republic of China
}

In $\mathrm{Na}^{+}$channels, recovery from inactivation begins with a delay, followed by an exponential course, and hyperpolarization shortens the delay as well as hastens the entire exponential phase. These findings have been taken to indicate that $\mathrm{Na}^{+}$channels must deactivate to recover from inactivation, and deactivation facilitates the unbinding of the inactivating particle. In contrast, it is demonstrated in this study that recovery from inactivation in Shaker $\mathrm{K}^{+}$channels begins with no delay on repolarization. Moreover, hyperpolarization hastens only the initial phase (fast component) of recovery yet retards the later phases of recovery by increasing the proportion of slow components. The time course of slow inward "tail" $\mathrm{K}^{+}$currents, which presumably result from the open state(s) traversed by the recovering inactivated channel, always matches the fast, but not the slow, components of recovery, suggesting that the fast and the slow components primarily correspond to recovery via the open state (unblocking of the inactivating particle before channel deactivation) and via the closed state (deactivation before unblocking), respectively. Besides, changing external $\mathrm{K}^{+}$concentration effectively alters the absolute value of the initial recovery speed, but not its voltage dependence. It seems that Shaker $\mathrm{K}^{+}$channel deactivation hinders, rather than facilitates, the unbinding of the inactivating particle and therefore retards recovery from inactivation, whereas external $\mathrm{K}^{+}$ may enhance unbinding of the inactivating particle by binding to a site located near the external entrance of the pore.

Key words: two-electrode voltage clamp; Shaker $K^{+}$channel; deactivation; ball and chain model of inactivation; recovery from inactivation; $\mathrm{K}^{+}$ion binding site
$\mathrm{K}^{+}$channels are important proteins controlling membrane excitability. Different $\mathrm{K}^{+}$channels may show different gating kinetics, which are crucial in considering the role of the channels in shaping cellular firing patterns (Rudy, 1988; Hille, 1992). The fast inactivation of Shaker $\mathrm{K}^{+}$channels is termed N-type inactivation, to be distinguished from the other, slower inactivation (Iverson and Rudy, 1990; Hoshi et al., 1991). Like in $\mathrm{Na}^{+}$channels, the development of N-type inactivation is explained by the "ball and chain" model (Armstrong and Bezanilla, 1977; Armstrong, 1981). According to the model, inactivation is produced by blocking the open channel with an inactivating particle (a peptide "ball"), which probably corresponds to the $\mathrm{N}$-terminal region of the Shaker $\mathrm{K}^{+}$channel protein (Hoshi et al., 1990; Zagotta et al., 1990)

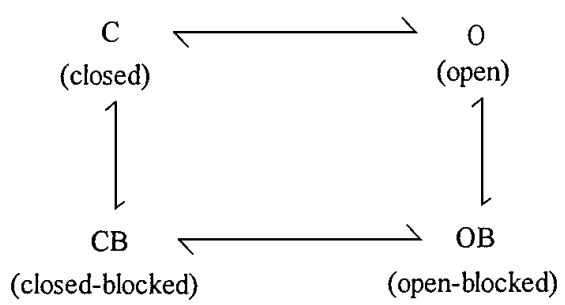

scheme 1

Received Jan. 3, 1997; revised Feb. 24, 1997; accepted Feb. 27, 1997.

This work was supported by Grant NSC 85-2331-B-002-154 from the National Science Council, Taiwan, Republic of China. I am very grateful to Dr. Bruce P. Bean for his kind advice and encouragement as well as for his generous support in equipment. I also thank Dr. Roderick MacKinnon for providing the Shaker GH4 cDNA as a gift.

Correspondence should be addressed to Dr. Chung-Chin Kuo, Department of Physiology, National Taiwan University College of Medicine, No. 1, Jen-Ai Road, First Section, Taipei 100, Taiwan, Republic of China.

Copyright (C) 1997 Society for Neuroscience 0270-6474/97/173436-09\$05.00/0
Above is a simplified gating scheme incorporating the foregoing concepts of fast inactivation, in which $\mathrm{OB}$ and $\mathrm{CB}$ denote open and closed conformations blocked by the inactivating particle, respectively. Basically, the route $\mathrm{C}$ to $\mathrm{O}$ to $\mathrm{OB}$ should be the major or even exclusive pathway for the development of inactivation so that inactivation is "coupled" to activation, and most channels would not be inactivated (blocked) until being "used" (open). On the other hand, the inactivated channel (state OB) in principle may recover via the $\mathrm{OB}$ to $\mathrm{O}$ to $\mathrm{C}$ (unblocking before deactivation) route or the $\mathrm{OB}$ to $\mathrm{CB}$ to $\mathrm{C}$ (deactivation before unblocking) route, and the two routes have very different physiological meanings. The former implies substantial ionic currents through the channels traversing state $\mathrm{O}$ during recovery, whereas the latter assures no such "leak" or "slow tail" currents on repolarization. It is interesting that $\mathrm{Na}^{+}$channels and Shaker $\mathrm{K}^{+}$ channels, although sharing similar molecular steps in the development of fast inactivation, seem to behave differently in recovering from inactivation. In $\mathrm{Na}^{+}$channels the "deactivation before unblocking" route seems to be exclusively preferred to assure negligible leak $\mathrm{Na}^{+}$currents during recovery (Kuo and Bean, 1994). On the other hand, many inactivated Shaker $\mathrm{K}^{+}$channels seem to take the $\mathrm{OB}$ to $\mathrm{O}$ to $\mathrm{C}$ route to recover because there are substantial macroscopic $\mathrm{K}^{+}$currents or single channel openings on repolarization (Demo and Yellen, 1991; Ruppersberg et al., 1991).

The $\mathrm{OB}$ to $\mathrm{O}$ to $\mathrm{C}$ route, however, may not be the exclusive pathway of recovery for inactivated Shaker $\mathrm{K}^{+}$channels. Demo and Yellen (1991) found that $8 \%$ recovery is via the closed state in $160 \mathrm{~mm}$ external $\mathrm{K}^{+}$at $-80 \mathrm{mV}$, and the percentage is higher at $-120 \mathrm{mV}$ or in $30 \mathrm{~mm}$ external $\mathrm{K}^{+}$, suggesting modulation of the recovery processes by membrane potentials and external $\mathrm{K}^{+}$. Because different recovery pathways imply different physiological 
consequences, it is desirable to explore the mechanisms modulating the molecular operations of recovery in Shaker $\mathrm{K}^{+}$channels in more detail. It is demonstrated herein that the modulatory effects of external $\mathrm{K}^{+}$and membrane potentials could be understood by kinetic interactions within a simplified gating scheme and that deactivation of the inactivated Shaker $\mathrm{K}^{+}$channel probably retards, rather than enhances, the exit of the bound inactivating particle.

\section{MATERIALS AND METHODS}

Molecular biology and oocyte injection. All experiments were performed with mRNA synthesized from the Shaker GH4 $\mathrm{K}^{+}$channel cDNA, which is essentially the same as Shaker H4 channel reported by Kamb et al. (1987), but with the addition of three "silent" restriction enzyme sites for $B g l \mathrm{II}, B s t \mathrm{II}$, and $S m a \mathrm{I}$, as well as a larger 5' untranslated region. Plasmids containing the ShGH4 cDNA were linearized by digestion with the appropriate restriction enzymes. Then linearized template cDNA was used for the synthesis of mRNA by standard methods, using T7 polymerase (MacKinnon and Yellen, 1990). Oocytes were harvested from mature Xenopus laevis females previously injected with human chorionic gonadotropin and dissociated in calcium-free OR-2 solution [(in $\mathrm{mM}$ ) 82.5 $\mathrm{NaCl}, 2.5 \mathrm{KCl}, 1 \mathrm{MgCl}_{2}$, and $\left.5 \mathrm{HEPES}\right]$ with collagenase (Type IA, 1-2 $\mathrm{mg} / \mathrm{ml}$; Sigma, St. Louis, MO) for 1-2 hr. Isolated, follicle-free stage V to stage VI oocytes were selected and injected with $50 \mathrm{nl}$ of synthetic mRNA in distilled water $(0.1-1 \mathrm{mg} / \mathrm{ml})$. Injected oocytes were maintained at $18^{\circ} \mathrm{C}$ in ND-96 solution [(in mM) $96 \mathrm{NaCl}, 2 \mathrm{KCl}, 1.8 \mathrm{CaCl}_{2}, 1 \mathrm{MgCl}_{2}$, and 5 HEPES plus $50 \mathrm{mg} / \mathrm{ml}$ gentamycin] until subsequent recordings. With daily change of the ND-96-maintaining solution, the injected oocytes usually survived for at least $7-10 \mathrm{~d}$.

Current recording and data analysis. Whole-cell Shaker $\mathrm{K}^{+}$channel currents from the injected oocytes were usually of decent size and suitable for recording 2-3 d after injection. For recordings, oocytes were transferred to a chamber with continuous superperfusion of $150 \mathrm{mM} \mathrm{K}^{+}$[(in mм) $150 \mathrm{KCl}, 1 \mathrm{CaCl}_{2}, 1 \mathrm{MgCl}_{2}$, and 10 HEPES, pH 7.4] or $150 \mathrm{~mm} \mathrm{Na}^{+}$ or 300 or $500 \mathrm{~mm} \mathrm{~K}^{+}$solutions. The composition of the latter three solutions is the same as that of the $150 \mathrm{mM} \mathrm{K}^{+}$solution, except that 150 $\mathrm{mm} \mathrm{KCl}$ is replaced by $150 \mathrm{~mm} \mathrm{NaCl}$ or 300 or $500 \mathrm{~mm} \mathrm{KCl}$, respectively. The 300 and $500 \mathrm{~mm} \mathrm{~K}^{+}$solutions are so hypertonic that the oocyte usually must go through one or two solutions of intermediate osmolarity (created by adding sucrose to ND-96) before being transferred into these recording solutions. Currents were measured at room temperature $\left(\sim 22^{\circ} \mathrm{C}\right)$ by a standard two-electrode voltage-clamp amplifier (Warner OC-725B-HV; Hamden, CT), supported by a 12 bit analog/digital converter controlled by a laboratory personal computer. Data were sampled at $5-10 \mathrm{kHz}$ and filtered at $2 \mathrm{kHz}$ (8-pole Bessel filter). Linear, digital leak subtraction was performed off-line using leak currents measured by a hyperpolarizing pulse from -80 to $-90 \mathrm{mV}$. Statistics are given as mean $\pm \mathrm{SD}$.

\section{RESULTS}

\section{The recovery from inactivation in Shaker $\mathrm{K}^{+}$channels begins with no delay in $150 \mathrm{~mm}$ external $\mathrm{K}^{+}$}

In $\mathrm{Na}^{+}$channels at the beginning of recovery there is a delay ascribable to the deactivation process (OB to $\mathrm{CB}$ in scheme 1) that the channel must go through before the inactivating particle could unblock (Kuo and Bean, 1994). If the inactivated Shaker K ${ }^{+}$ channel may recover via the $\mathrm{OB}$ to $\mathrm{O}$ to $\mathrm{C}$ route, then no intermediate step is needed for the inactivating particle to unblock, and the recovery therefore should begin with no delay. Figure 1 characterizes this very initial phase of recovery in Shaker $\mathrm{K}^{+}$channels. Figure $1 A$ monitors the voltage change of an oocyte in the two-electrode voltage clamp, showing faithful voltage control with satisfactory "clamp speed." The voltage change is typically $>60 \%$ in $0.1 \mathrm{msec}$ and essentially is completed after 0.3 msec. Figure $1 B$ illustrates that at either $-70 \mathrm{mV}$ or $-220 \mathrm{mV}$ there is always unequivocal recovery during the first $0.2 \mathrm{msec}$ of repolarization. This is consistent with previous reports (Demo and Yellen, 1991; Ruppersberg et al., 1991) and suggests that in 150 $\mathrm{mm}$ external $\mathrm{K}^{+}$many inactivated Shaker $\mathrm{K}^{+}$channels take the
$\mathrm{OB}$ to $\mathrm{O}$ route to recover from inactivation. Because the rate of development of C-type inactivation in wild-type Shaker H4 channels is $\sim 1-2 \mathrm{sec}^{-1}$ in $10-100 \mathrm{~mm}$ external $\mathrm{K}^{+}$(Baukrowitz and Yellen, 1995), all inactivating pulses used in this study have been kept short $(30-60 \mathrm{msec})$ to avoid significant contamination from other, slower inactivation process than $\mathrm{N}$-type inactivation. This also is checked by examining the current of those Shaker GH4 channels for which the N-type inactivation is removed by deleting amino acid residues 6-46 (in 10-100 mM external $\mathrm{K}^{+}$the rate of development of C-type inactivation in these mutated channels is not very different from that in wild-type channels; see Baukrowitz and Yellen, 1995). It is found that the currents generally decrease by no more than $3-5 \%$ over such short depolarizing pulses (see also Heginbotham and MacKinnon, 1993) (data not shown). Thus C-type or other, slower inactivation probably could be disregarded, and the consideration would be focused on $\mathrm{N}$-type inactivation.

\section{The initial recovery rates increase consistently with increasing hyperpolarization in $150 \mathrm{~mm}$ external $\mathrm{K}^{+}$}

Figure $1 C$ depicts the time courses of recovery in the first $\sim 3 \mathrm{msec}$ of repolarization. The recovery begins with no delay and follows an initial linear course, the slope of which is larger at more negative potentials. Figure $1 D$ plots a common logarithm of the slope against membrane potential, with a regression line to indicate that the initial recovery rate consistently increases $e$-fold per $\sim 90 \mathrm{mV}$ of hyperpolarization between -70 and $-250 \mathrm{mV}$. Another interesting finding in Figure $1 C$ is that the time course at $-250 \mathrm{mV}$ appears to "bend" more than the course at $-190 \mathrm{mV}$ when the recovery fraction exceeds $\sim 0.3$. Thus the time courses at $-190 \mathrm{mV}$ to $-250 \mathrm{mV}$ are clearly apart at the beginning yet are converging at $\sim 3 \mathrm{msec}$. This implies that hyperpolarization probably accelerates only the early phase, but not the late phase, of recovery.

\section{Strong hyperpolarization increases the proportion of a late slow recovery phase}

The effect of hyperpolarization on the late recovery phase is investigated by examining the complete time courses of recovery in Figure 2. Figure $2 A$ shows that the recovery courses at -40 to $-100 \mathrm{mV}$ are all essentially completed within $100 \mathrm{msec}$ and can be approximated by monoexponential functions. At $-130 \mathrm{mV}$ or more negative potentials the recovery courses can be described only by two-exponential functions and start to "cross" each other (Fig. 2B), clearly indicating that increasing hyperpolarization hastens the initial phase, but not the late phase, of recovery. The fast time constants of these twoexponential recovery courses become smaller with increasing hyperpolarization (approximately $e$-fold change per $60 \mathrm{mV}$, Fig. $2 C$ ). On the other hand, the slow time constants of these courses seem to be voltage-independent (Fig. 2D), although the proportion of the slow components increases as the membrane potential gets more negative (Fig. 2E).

\section{The slow component of recovery represents recovery via the deactivated states}

Because increasing hyperpolarization hastens the entire course of recovery in $\mathrm{Na}^{+}$channels (Kuo and Bean, 1994), it is very interesting to see that stronger hyperpolarization hastens only the immediate recovery from inactivation yet drives more inactivated channels into some other states from which recovery is actually retarded. Based on scheme 1, a most straightforward explanation for these findings would be that increasing hyper- 
A
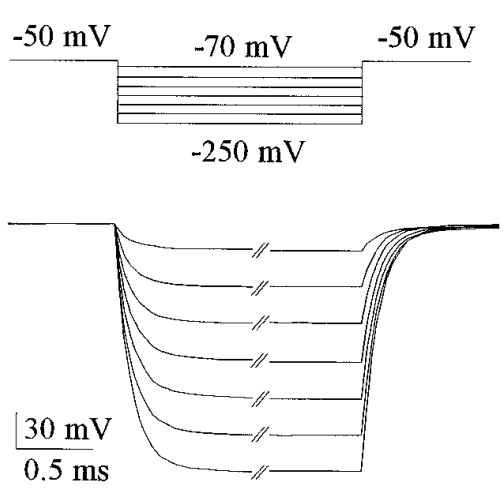

B
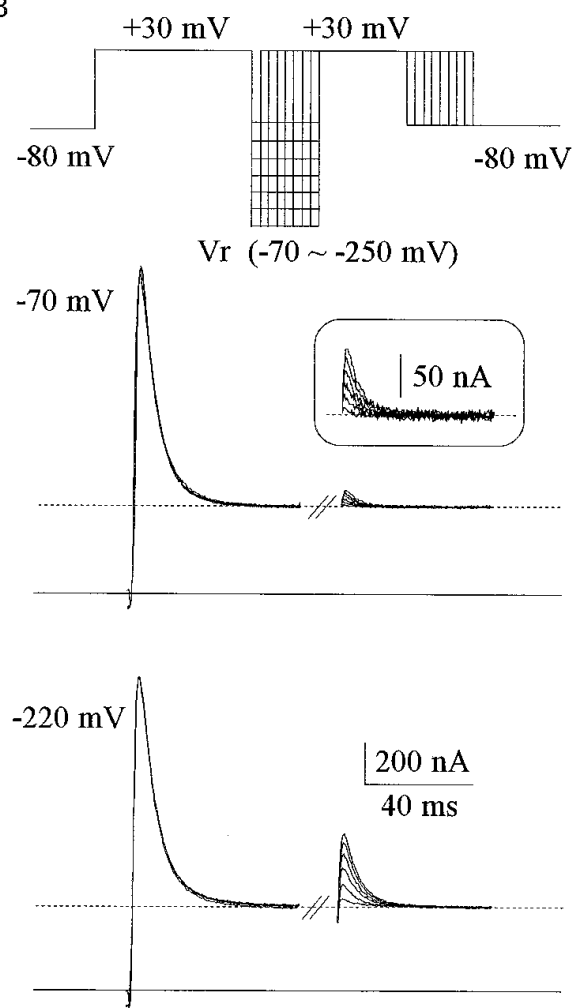

$\mathrm{C}$

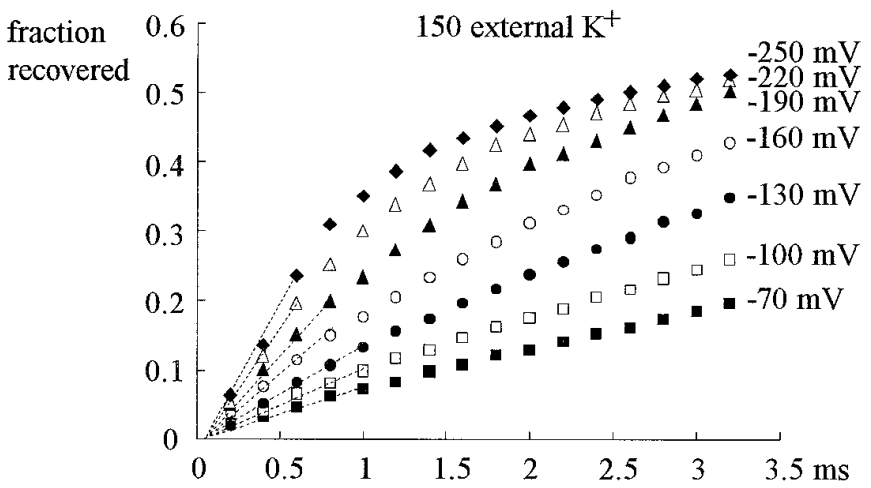

$\mathrm{D}$

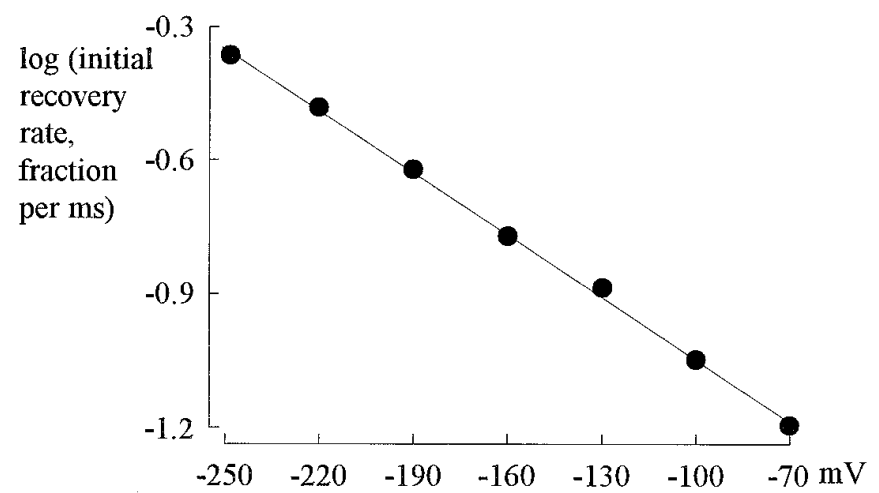

Figure 1. Initial phase of recovery in $150 \mathrm{~mm}$ external $\mathrm{K}^{+} . A$, Examination of the speed of voltage change and steady-state voltage control in two-electrode voltage clamp of an oocyte. The voltage change is $62 \%$ (of total) at $0.1 \mathrm{msec}, 83 \%$ at $0.2 \mathrm{msec}, 95 \%$ at $0.3 \mathrm{msec}$, and $\sim 99 \%$ at $0.4 \mathrm{msec}$. $B$, The oocyte was held at $-80 \mathrm{mV}$ and pulsed twice to $+30 \mathrm{mV}$ (each for $60 \mathrm{msec}$ ) every $3 \mathrm{sec}$. The intervening gap between the two pulses is set at various potentials (recovery potential, $V r$ ) and lengthened by $0.2 \mathrm{msec}$ between each sweep. The currents in the second pulse are used as a measure of the extent of recovery from inactivation produced by the first pulse. No matter that $V r$ is $-70 \mathrm{mV}$ or $-220 \mathrm{mV}$ (inset is an enlarged redrawing of the currents for $V r-70 \mathrm{mV}$ ), the currents in the second pulse appear within $0.2 \mathrm{msec}$. The initial rate of recovery, however, is faster at more negative $V r$. The solid lines denote zero current level, and the dashed lines mark the sustained (noninactivating) current level. $C$, Time courses of recovery in the first $\sim 3$ msec for $V r-70 \mathrm{mV}$ to $-250 \mathrm{mV}$ by the same experimental protocol as that in $B$. The horizontal axis is the length of $V r$. The vertical axis is the extent of recovery (fraction recovered), which is the difference between the peak current of the second pulse and the current at the end of first pulse, divided by the difference between the peak current of the first pulse and the current at the end of the first pulse. The first three to five points at each potential are fit by linear regression functions (dashed lines) of the form: fraction recovered $=$ slope $\cdot t(t$ denotes length of $V r$ in $\mathrm{msec}$ ), in which slope equals $0.060(-70 \mathrm{mV})$, $0.085(-100 \mathrm{mV}), 0.12(-130 \mathrm{mV}), 0.17(-160 \mathrm{mV}), 0.25(-190 \mathrm{mV}), 0.33(-220 \mathrm{mV})$, and $0.43(-250 \mathrm{mV})$. $D$, The common logarithms of the slopes of the regression lines in $C$ are plotted against $V r$. The solid line is a linear regression fit of the form: $y=-1.52-0.0047 x$, indicating that the initial recovery rate increases $e$-fold per $\sim 90 \mathrm{mV}[(\log e) / 0.0047=92]$ of hyperpolarization.

polarization not only speeds the unblocking of the inactivating particle from the open-blocked channel (OB to $\mathrm{O}$ or the initial recovery rate) but also enhances deactivation of the openblocked channels (OB to $\mathrm{CB}$ ). The essentially unchanged time constants of the slow component of recovery in Figure $2 D$ then would suggest that $\mathrm{CB}$ to $\mathrm{C}$ is the slower (rate-limiting) step of the $\mathrm{OB}$ to $\mathrm{CB}$ to $\mathrm{C}$ route and possibly is not voltage-dependent. It has been shown that the recovery from inactivation in Shaker $\mathrm{K}^{+}$channels is accompanied by prominent inward "slow" tail $\mathrm{K}^{+}$current in $150 \mathrm{~mm}$ external $\mathrm{K}^{+}$(Demo and Yellen, 1991; 
A

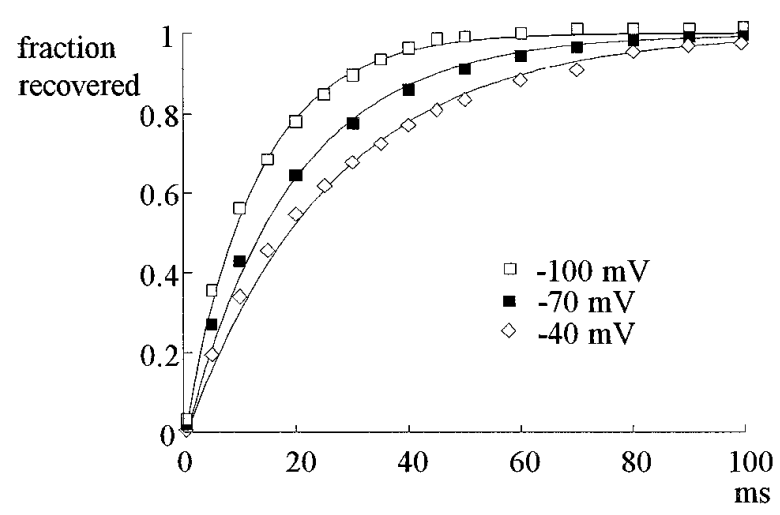

B

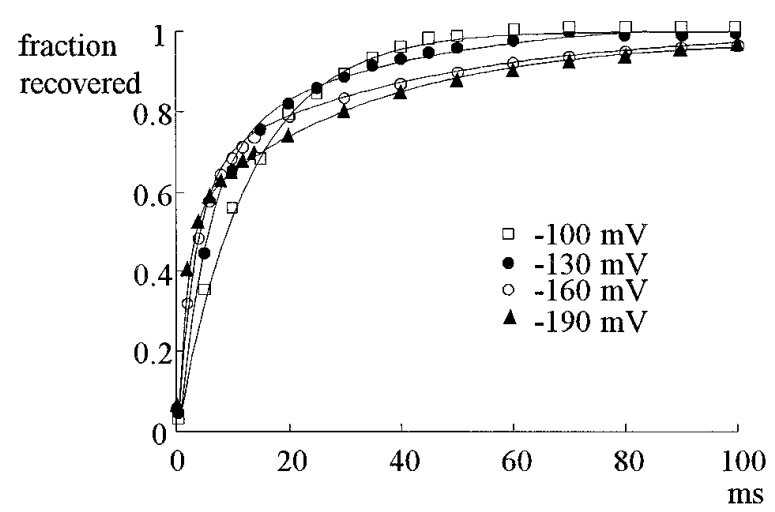

$\mathrm{C}$

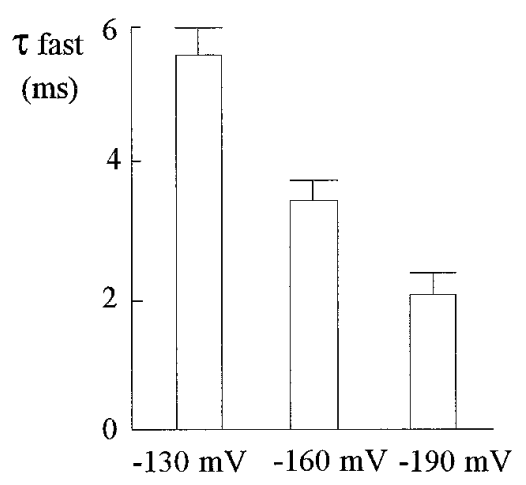

$\mathrm{D}$

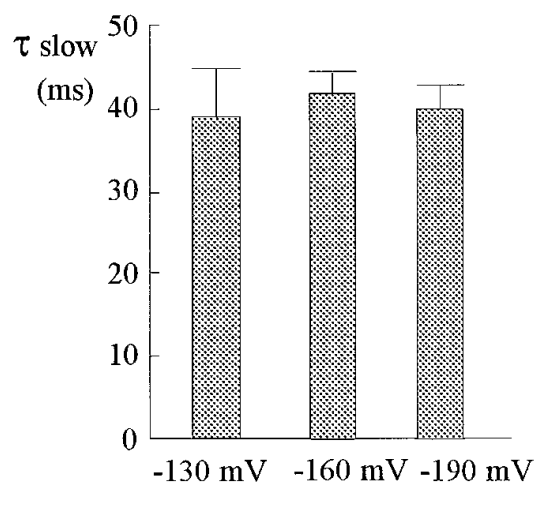

E

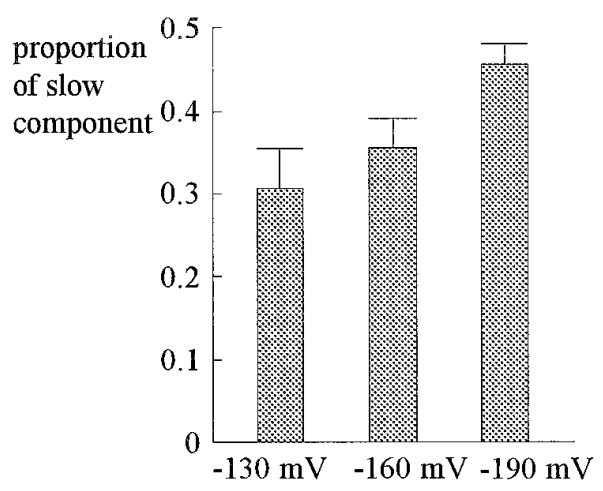

Figure 2. Extended time course of recovery in $150 \mathrm{~mm}$ external $\mathrm{K}^{+} . A$, Time courses of recovery at $V r-40,-70$, and $-100 \mathrm{mV}$. Voltage protocols and plots are as in Figure 1 except that the length of $V r$ is much longer here. Smooth curves are monoexponential fits of the form: fraction recovered $=1-$ $\exp (-t / \tau)(t$ denotes length of $V r$, the horizontal axis), in which $\tau$ equals $27.2,19.0$, and $12.7 \mathrm{msec}$ for the data in $-40,-70$, and $-100 \mathrm{mV}$, respectively. $B$, Time courses are similar to those in $A$ but are at $V r-130,-160$, and $-190 \mathrm{mV}$, with the time course at $V r-100 \mathrm{mV}$ in $A$ plotted here again for comparison. Note that the time courses "cross" each other. The smooth curves are two-exponential fits of the form: fraction recovered $=1-0.64 \cdot$ $\exp (-t / 5.3)-0.36 \cdot \exp (-t / 32)(-130 \mathrm{mV}),=1-0.61 \cdot \exp (-t / 3.2)-0.39 \cdot \exp (-t / 44)(-160 \mathrm{mV})$, and $=1-0.55 \cdot \exp (-t / 1.9)-0.45 \cdot \exp (-t / 38)$ $(-190 \mathrm{mV}) . C$, The fast time constants from the two-exponential fits in four cells are $5.6 \pm 0.4 \mathrm{msec}(-130 \mathrm{mV}), 3.4 \pm 0.3 \mathrm{msec}(-160 \mathrm{mV})$, and $2.1 \pm$ $0.3 \mathrm{msec}(-190 \mathrm{mV}) . D$, The slow time constants from the same data pool in $C$ are apparently voltage-independent and are $39 \pm 6 \mathrm{msec}(-130 \mathrm{mV})$, $42 \pm 2 \mathrm{msec}(-160 \mathrm{mV})$, and $40 \pm 3 \mathrm{msec}(-190 \mathrm{mV}) . E$, The proportion (preexponential factor) of the slow component from the same data pool in $C$ increases with increasing hyperpolarization $(0.31 \pm 0.05$ at $-130 \mathrm{mV}, 0.36 \pm 0.03$ at $-160 \mathrm{mV}$, and $0.46 \pm 0.02$ at $-190 \mathrm{mV})$.

Gomez-Lagunas and Armstrong, 1994), which presumably results from the traversed open state during recovery (route OB to $\mathrm{O}$ to $\mathrm{C}$ in scheme 1 ). If the slow component primarily corresponds to recovery via the $\mathrm{OB}$ to $\mathrm{CB}$ to $\mathrm{C}$ route, then it should not be accompanied by significant tail currents. Figure
$3 A$ examines the slow tail currents, which match the fast components of macroscopic recovery in time course at various potentials (Fig. $3 B$ ) and clearly contain no "slow" phase corresponding to the slow component of recovery. This finding lends strong support for the view that the slow component of 
A

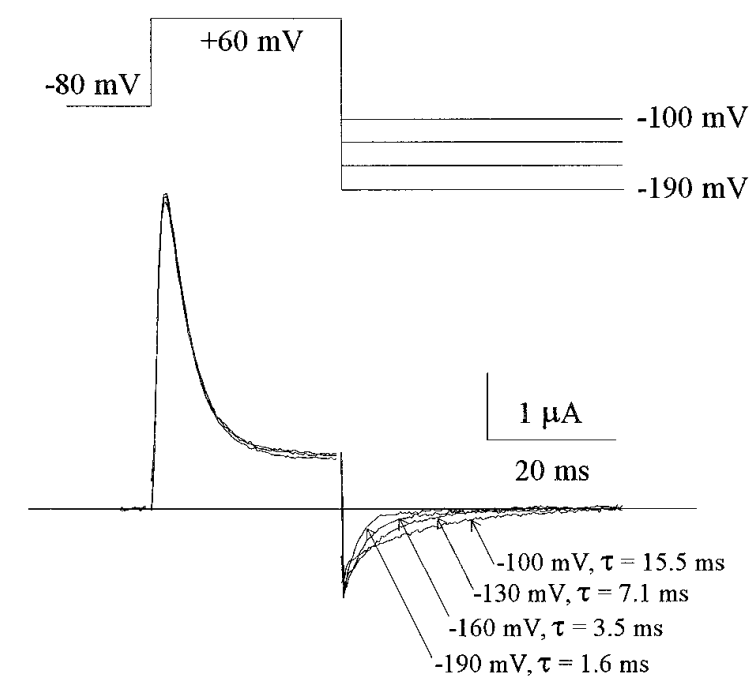

B

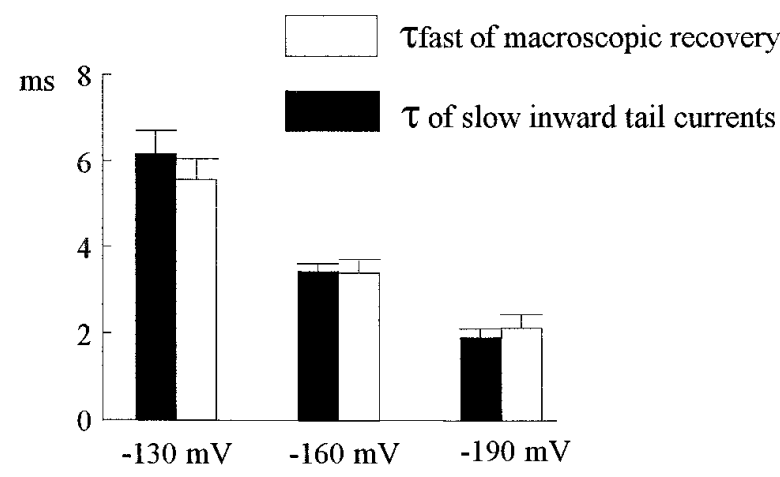

Figure 3. The slow inward tail currents at various repolarizing potentials in $150 \mathrm{~mm}$ external $\mathrm{K}^{+} . A$, The oocyte is held at $-80 \mathrm{mV}$ and pulsed every $3 \mathrm{sec}$ to $+60 \mathrm{mV}$ for $30 \mathrm{msec}$ and then repolarized to various potentials for $45 \mathrm{msec}$ to demonstrate the slow inward tail currents. $B$, The decaying time constants of the slow inward tail currents from four cells are $6.1 \pm 0.6$ $\mathrm{msec}(-130 \mathrm{mV}), 3.4 \pm 0.2 \mathrm{msec}(-160 \mathrm{mV})$, and $1.9 \pm 0.2 \mathrm{msec}(-190$ $\mathrm{mV}$ ), which correlate well with the fast time constants of macroscopic recovery (the same data as those in Fig. $2 C$ ) at various repolarizing potentials.

recovery primarily results from those inactivated channels recovering via the $\mathrm{OB}$ to $\mathrm{CB}$ to $\mathrm{C}$ route.

\section{The initial recovery rates in $150 \mathrm{~mm}$ external $\mathrm{Na}^{+}$ are remarkably slower but carry the same voltage dependence}

The recovery from inactivation was reexamined over the same wide range of repolarizing potentials in an external solution containing $150 \mathrm{mM} \mathrm{Na}{ }^{+}$, but no $\mathrm{K}^{+}$. Strictly speaking, this is not a condition of "zero" but only "low" external $\mathrm{K}^{+}$, because with the two-pulse protocol used here the $\mathrm{K}^{+}$ions flowing out during the first pulse may not be dissipated fully before the repolarizing pulse (the local residual $\mathrm{K}^{+}$concentration is possibly $10-15 \mathrm{~mm}$ when checked by the reversal potential of the deactivating tail currents that follow a short depolarization pulse; data not shown). Similar to the findings in $150 \mathrm{~mm}$ external $\mathrm{K}^{+}$, the initial recovery phase in $150 \mathrm{mM} \mathrm{Na}^{+}$(Fig. 4A) follows a linear course, the slope of which, however, is consistently four to five times smaller than the slope at the same repolarizing potential in Figure 1C. Figure $4 B$ plots a common logarithm of the slopes in Figure $4 A$ against membrane potential, with a regression line having the same slope as, but a $y$-intercept 0.67 smaller than, the regression line in Figure $1 D$. This indicates that in $150 \mathrm{~mm}$ external $\mathrm{Na}^{+}$the initial recovery rates also increase $e$-fold per $\sim 90 \mathrm{mV}$ of hyperpolarization yet are, in general, $10^{0.67}$ or $\sim 4.7$ times slower than those in $150 \mathrm{~mm}$ $\mathrm{K}^{+}$at every potential tested. The same experiments also are performed in 300 and $500 \mathrm{~mm}$ external $\mathrm{K}^{+}$. The $y$-intercepts of the regression lines similar to those in Figures $1 D$ and $4 B$ on average differ by 0.66 between $150 \mathrm{~mm}$ external $\mathrm{Na}^{+}$and $150 \mathrm{~mm}$ external $\mathrm{K}^{+}$but show no difference among 150,300 , and $500 \mathrm{~mm}$ external $\mathrm{K}^{+}$(Fig. $4 C$ ). The slopes of these regression lines, on the other hand, always remain the same in either very low or very high external $\mathrm{K}^{+}$(Fig. $4 D$ ).

\section{There is a very slow component of macroscopic recovery in low external $\mathrm{K}^{+}$}

Figure $5 A$ shows more extended time courses of recovery up to $100 \mathrm{msec}$ in $150 \mathrm{~mm}$ external $\mathrm{Na}^{+}$. The time courses also cross each other like those in Figure $2 B$. At $-160 \mathrm{mV}$ or more negative potentials, the time courses can be described only by two-exponential functions, and the fast time constants are smaller as the membrane potential goes more negative (Fig. $5 B$ ). For the late phase of recovery, it is noteworthy that in 150 mM external $\mathrm{Na}^{+}$the recovery at $100 \mathrm{msec}$ is clearly not complete at these negative potentials. This phenomenon is more pronounced at more negative potentials (Fig. 5A) as if, other than the fast and slow components, there are some "very slow" components of recovery. Although C-type or other slow inactivation may become more prevalent in low external $\mathrm{K}^{+}$ (Baukrowitz and Yellen, 1995), it is hard to envisage how these very slow components, if resulting from C-type inactivation, should become more pronounced at more negative repolarizing potentials. An alternative to explain this phenomenon is to make scheme 1 less oversimplified by adding more closed states (see scheme 2 below, in which $-V$ denotes those hyperpolarization-accelerated key processes under discussion here). Because the initial recovery rate ( $\mathrm{OB}$ to $\mathrm{O}$ rate) is quite slower in low external $\mathrm{K}^{+}$than in high external $\mathrm{K}^{+}$(Figs. $1 C$, $4 A$ ), the chance of taking the $\mathrm{OB}$ to $\mathrm{CB}$ route, and consequently the chance of reaching state $\mathrm{C}^{\prime} \mathrm{B}$, would be higher in low $\mathrm{K}^{+}$. With scheme 2 the very slow component of recovery may be explained by a hypothesis that some inactivated channels are moved into the $\mathrm{C}^{\prime} \mathrm{B}$ state, along with a very slow unblocking rate from the more completely deactivated state (very slow $\mathrm{C}^{\prime} \mathrm{B}$ to $\mathrm{C}^{\prime}$ rate).

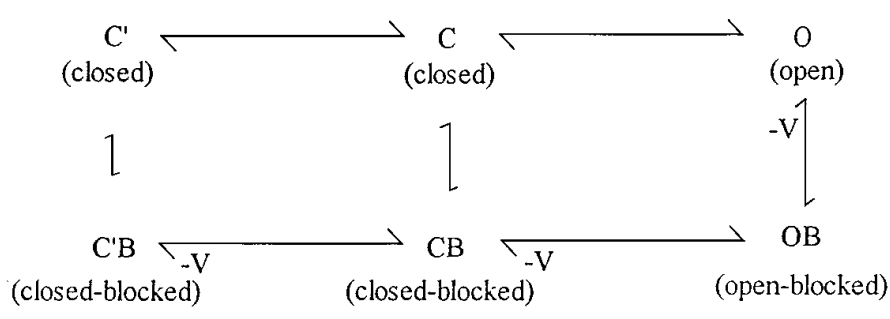

scheme 2 
A

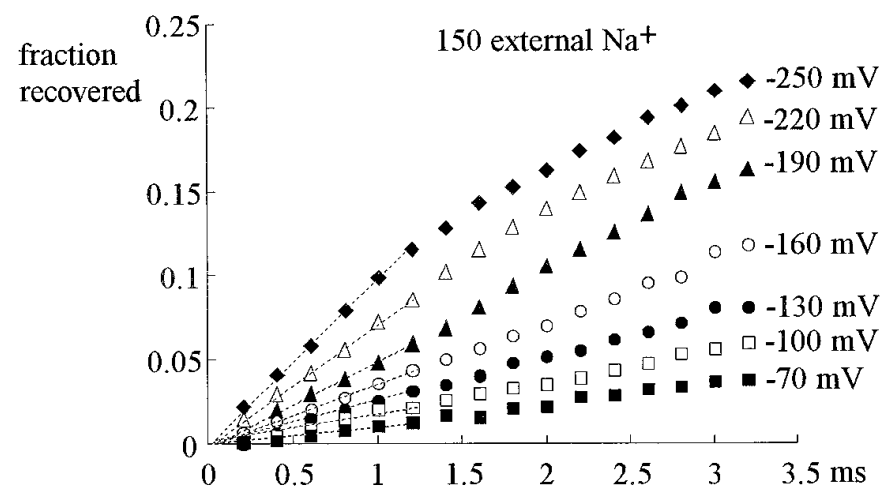

$\mathrm{B}$

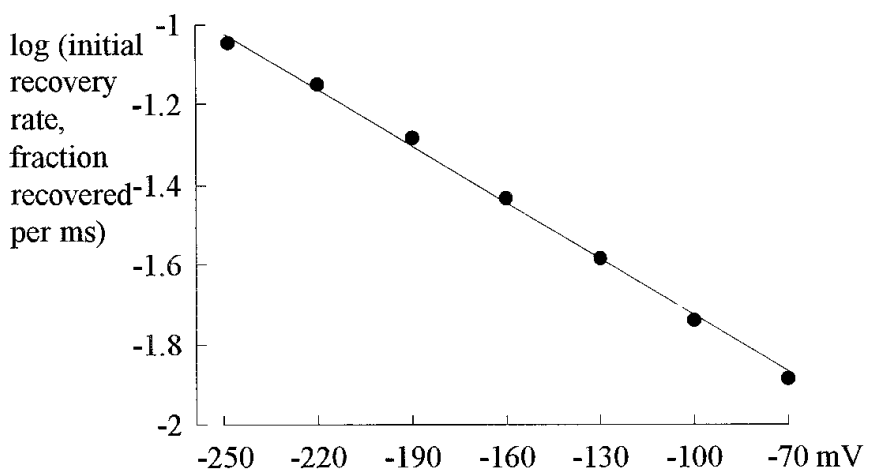

$\mathrm{C}$

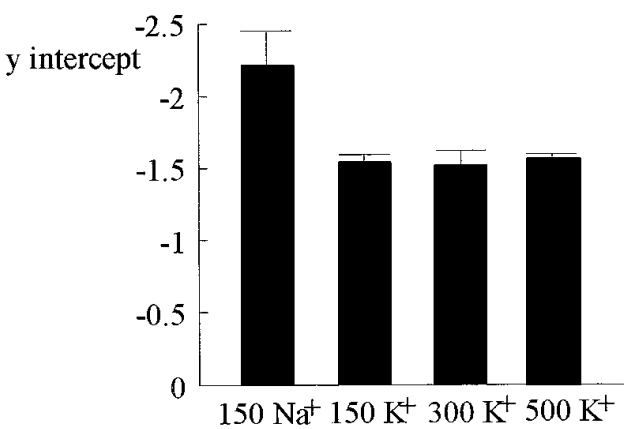

$\mathrm{D}$

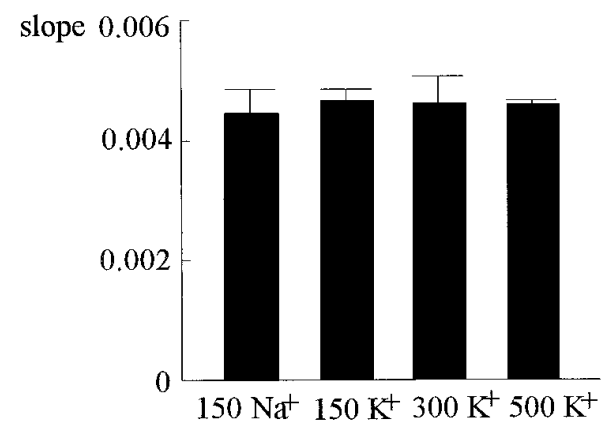

Figure 4. Initial phase of recovery in $150 \mathrm{~mm}$ external $\mathrm{Na}^{+} . A$, Time courses are similar to Figure $1 C$ on the basis of the same experimental protocols. The first six points at each potential are fit by linear regression functions (dashed lines) of the form: fraction recovered $=$ slope $\cdot t$, in which slope equals $0.013(-70 \mathrm{mV}), 0.019(-100 \mathrm{mV}), 0.026(-130 \mathrm{mV}), 0.037(-160 \mathrm{mV}), 0.052(-190 \mathrm{mV}), 0.07(-220 \mathrm{mV})$, and $0.09(-250 \mathrm{mV}) . B$, The common logarithms of the slopes of the regression lines in $A$ are plotted against $V r$. The solid line is a linear regression fit of the form: $y=-2.19-0.0047 x$. $C$, The $y$-intercepts of regression lines similar to that in $B$ in various external solutions are $-2.21 \pm 0.25\left(150 \mathrm{mM}^{+}\right.$external Na${ }^{+}, 5$ cells $),-1.55 \pm 0.04(150$ $\mathrm{mm}$ external $\mathrm{K}^{+}, 4$ cells $),-1.51 \pm 0.11\left(300 \mathrm{~mm}\right.$ external $\mathrm{K}^{+}, 3$ cells $)$, and $-1.57 \pm 0.03\left(500 \mathrm{~mm}\right.$ external $\mathrm{K}^{+}, 3$ cells $)$. $D$, The slopes of the regression lines in $C$ are $0.0045 \pm 0.0004\left(150 \mathrm{mM} \mathrm{Na}^{+}\right), 0.0047 \pm 0.0002\left(150 \mathrm{mM} \mathrm{K}^{+}\right), 0.0046 \pm 0.0005\left(300 \mathrm{~mm} \mathrm{~K}^{+}\right)$, and $0.0046 \pm 0.0001\left(500 \mathrm{~mm} \mathrm{~K}^{+}\right)$.

\section{The very slow component of recovery also is observed in high external $\mathrm{K}^{+}$at extremely negative potentials}

Considering that increased hyperpolarization would increase the chance for a channel in state $\mathrm{OB}$ to recover via the $\mathrm{OB}$ to $\mathrm{CB}$ route (Fig. 2E), if the very slow component of macroscopic recovery in low external $\mathrm{K}^{+}$is indeed a result of simple kinetic interactions rather than an effect of external $\mathrm{K}^{+}$on some slow inactivation processes, then the very slow components of recovery should become manifest even in high external $\mathrm{K}^{+}$at very negative recovery potentials. Figure 6 illustrates that in $300 \mathrm{~mm}$ external $\mathrm{K}^{+}$the recovery essentially is complete after $100 \mathrm{msec}$ at -130 $\mathrm{mV}$, whereas at $-250 \mathrm{mV}$ a very slow component ( $\sim 20 \%$ of total) of macroscopic recovery similar to that observed in Figure 5 occurs, and the recovery clearly is incomplete after the same 100 msec period.

\section{DISCUSSION}

\section{Quantitative analysis and support of the gating scheme}

In this study the fast or initial phase of recovery from inactivation is characterized in several different ways, namely the linear regression for the initial recovery rates, the exponential fit for extended recovery time courses, and the decay of the slow inward tail currents during recovery. The relationship among these measurements may be derived analytically on the basis of a more elaborated form of scheme 2 (Fig. 7). Focusing on the fast recovery ( $\mathrm{OB}$ to $\mathrm{CB}$ to $\mathrm{C}$ ) route, we have:

$$
\begin{gathered}
d \mathrm{C}(t) / d t=\delta \cdot \mathrm{O}(t) \\
d \mathrm{O}(t) / d t=\alpha \cdot \mathrm{OB}(t)-\delta \cdot \mathrm{O}(t) \\
\mathrm{OB}(t)=\mathrm{OB}(0) \cdot \exp [-(\alpha+\gamma) \cdot t]
\end{gathered}
$$

in which $\mathrm{OB}(0)$ denotes the fraction of $\mathrm{OB}$ at the beginning of repolarization, and $t$ denotes time. The reverse reactions $\mathrm{C}$ to $\mathrm{O}$ and $\mathrm{CB}$ to $\mathrm{OB}$ are assumed negligible at the hyperpolarized recovery potentials. The reaction $\mathrm{O}$ to $\mathrm{OB}$ also is neglected, because most channels in state $\mathrm{O}$ would be "absorbed" to state $\mathrm{C}$ because of the very rapid $\delta\left(>2 \mathrm{msec}^{-1}\right.$ at $-100 \mathrm{mV}$, measured by the decay of the deactivating tail currents after a short activating pulse; data not shown) and the slow $\mathrm{O}$ to $\mathrm{OB}$ rate $\left(\sim 0.1 \mathrm{msec}^{-1}\right.$, measured by the decay of the macroscopic outward currents at $+60 \mathrm{mV})$. Solve the equations for $\mathrm{O}(t)$ and $\mathrm{C}(t)$ : 
A

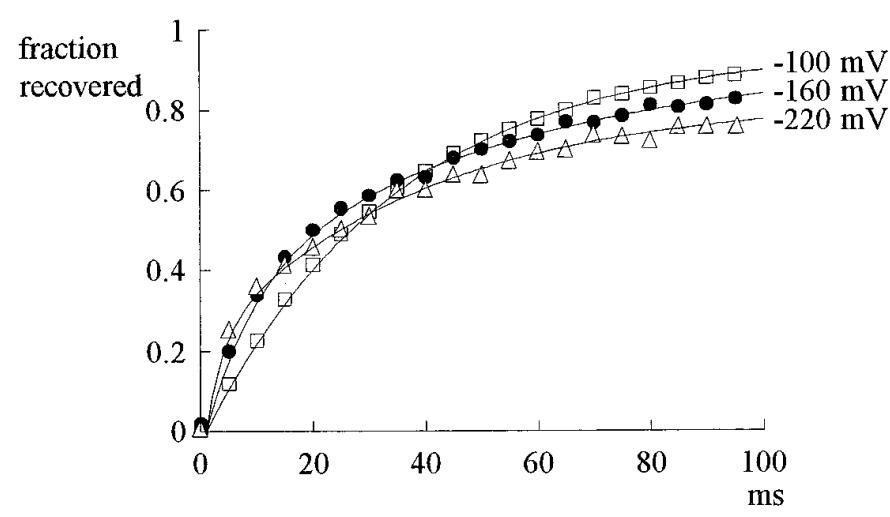

B

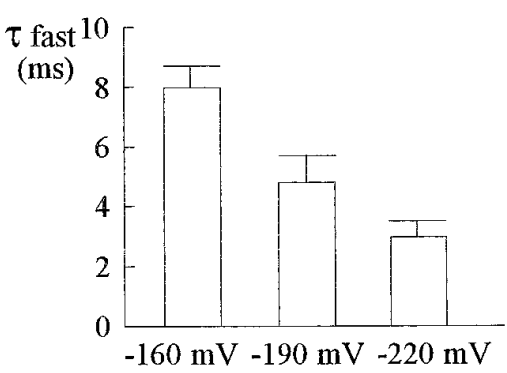

Figure 5. Extended time courses of macroscopic recovery in $150 \mathrm{~mm}$ external $\mathrm{Na}^{+}$. $A$, Time courses of recovery at recovery potential $(V r)$ $-100,-160$, and $-220 \mathrm{mV}$. Voltage protocols and plots are as in Figure 2. The time courses also "cross" each other, yet the recovery at $100 \mathrm{msec}$ becomes incomplete, especially at more negative $V r$. The smooth curves are mono- or two-exponential fits of the form: fraction recovered $=0.95-$ $0.95 \cdot \exp (-t / 37)(-100 \mathrm{mV}),=0.92-0.35 \cdot \exp (-t / 8.6)-0.57 \cdot$ $\exp (-t / 53)(-160 \mathrm{mV})$, and $=0.82-0.22 \cdot \exp (-t / 3.3)-0.60 \cdot \exp (-t /$ 39) $(-220 \mathrm{mV}) . B$, The fast time constants from the two-exponential fits in three cells are $8.0 \pm 0.7 \mathrm{msec}(-160 \mathrm{mV}), 4.8 \pm 0.9 \mathrm{msec}(-190 \mathrm{mV})$, and $3.0 \pm 0.5 \mathrm{msec}(-220 \mathrm{mV})$.

$$
\begin{gathered}
\mathrm{O}(t)=\{\alpha \cdot \mathrm{OB}(0) /[\delta-(\alpha+\gamma)]\} \cdot\{\exp [-(\alpha+\gamma) \cdot t] \\
-\exp (-\delta t)\} ; \text { and } \\
\mathrm{C}(t)+\mathrm{O}(t)=[\alpha \cdot \mathrm{OB}(0) /(\alpha+\gamma)] \cdot\{1-\exp [-(\alpha+\gamma) \cdot t]\} .
\end{gathered}
$$

$\mathrm{C}(t)+\mathrm{O}(t)$ here is the extent of the fast component of recovery. If the initial recovery rate (Fig. $1 C$ ) represents the $\mathrm{OB}$ to $\mathrm{O}$ rate $(\alpha)$, it should be equal to the product of the inverse of the fast time constant $(\alpha+\gamma)$ and the proportion of the fast component of the extended recovery time course $[\alpha /(\alpha+\gamma)]$. This seems true by comparing such products from the time courses at -70 to -190 $\mathrm{mV}$ in Figure 2 and the initial recovery rates at the same potentials in Figure $1 C$. Furthermore, the slow inward tail current at repolarization represents the proportion of state $\mathrm{O}$ as a function of time, $\mathrm{O}(t)$. Because $\delta$ is quite faster than $(\alpha+\gamma)$, according to the above equation $\mathrm{O}(t)$ would approximate a monoexponential decaying function (after a transient initial rising phase) with a time constant of $1 /(\alpha+\gamma)$, the foregoing fast time constant. These are just the findings in Figure 3.

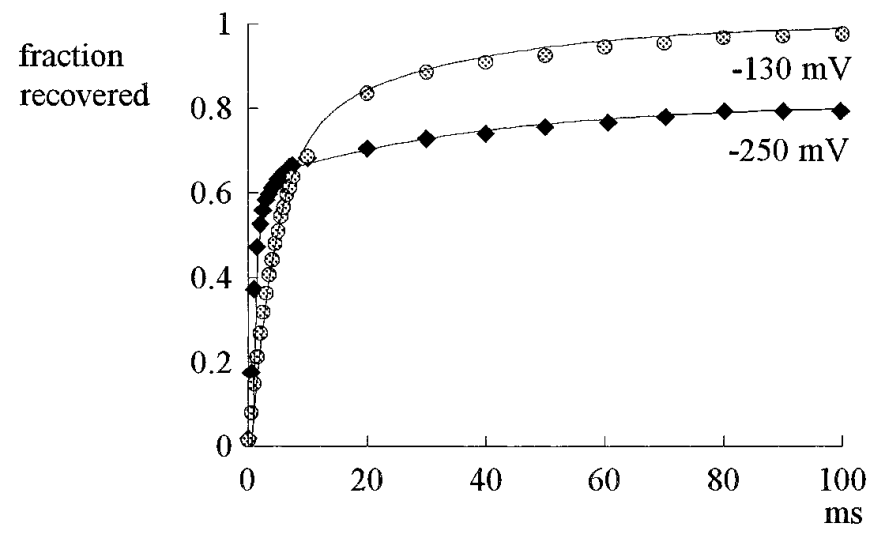

Figure 6. Recovery time course at extremely negative recovery potential $(V r)$ in $300 \mathrm{~mm}$ external $\mathrm{K}^{+}$. Voltage protocols and plots are as in Figure 2. At $V r-130 \mathrm{mV}$, the recovery essentially is complete at $100 \mathrm{msec}$, whereas at $V r-250 \mathrm{mV}$ the recovery is far from complete at $100 \mathrm{msec}$. The smooth curves are two-exponential fits of the form: fraction recovered $=1-0.75 \cdot \exp (-t / 5.1)-0.25 \cdot \exp (-t / 41)(-130 \mathrm{mV})$, and $=$ $0.81-0.63 \cdot \exp (-t / 0.9)-0.18 \cdot \exp (-t / 42)(-250 \mathrm{mV})$.

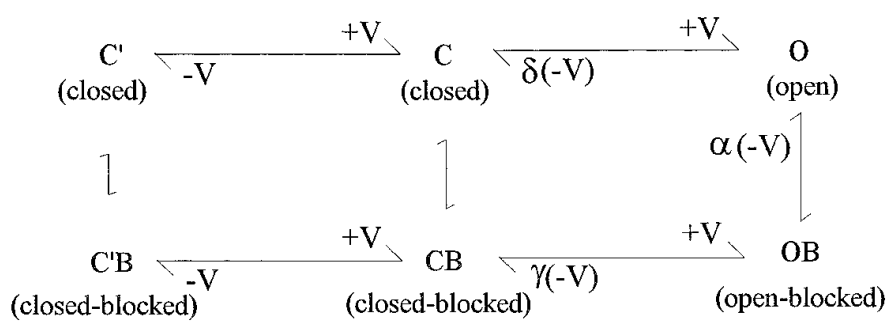

Figure 7. An elaboration of scheme 2 summarizing the findings. $+V$ and $-V$ mean that a reaction process is accelerated with depolarization and hyperpolarization, respectively. Because the unbinding rates of the inactivating particle are smaller from the more deactivated channel, the binding rates onto the more deactivated channel also must be smaller so that channel inactivation is still coupled to activation. The longitudinal arrows, therefore, are made smaller toward the left side of the scheme. The rate constants of some key steps in the scheme are $\left(\right.$ all in $\left.\mathrm{msec}^{-1}\right)$ : unbinding rate from the OB state, $\alpha$ (in $150 \mathrm{~mm}$ external $\mathrm{K}^{+}$) $=0.028$. $\exp (V m /-90)$ or $\alpha$ (in $150 \mathrm{~mm}$ external $\left.\mathrm{Na}^{+}\right)=0.006 \cdot \exp (V m /-90)$, in which $V m$ denotes membrane potential; deactivation rate of the OB state, $\gamma=0.003 \cdot \exp (V m /-47)$; deactivation rate from the $\mathrm{O}$ state, $\delta>2$ at $-100 \mathrm{mV}$ and even faster at more negative potentials. These numbers mostly are derived directly from the experimental findings, except that $\gamma$ is a postulated function to well recapitulate the observed proportions of fast and slow components of recovery. The unbinding rate from the $\mathrm{CB}$ state ( $\mathrm{CB}$ to $\mathrm{C}$ rate) may be set at a voltage-independent value $\sim 0.025 \mathrm{msec}^{-1}$, because the slow time constants of the recovery course are always $\sim 40$ msec at -130 to $-190 \mathrm{mV}$. Such voltage independence, in contrast to the definite voltage dependence of $\alpha$, implies that the activation-deactivation conformational changes alter the electrical lines across the pore; thus, the bound inactivating particle could no longer sense the electrical field in the closed channel.

Some other findings also may be discussed in the light of the same quantitative arguments. For example, the initial recovery rates $(\alpha)$ are accelerated consistently $e$-fold per $90 \mathrm{mV}$ hyperpolarization between -70 and $-250 \mathrm{mV}$ (Figs. $1 D, 4 B$ ), whereas the voltage dependence of the fast time constants $[1 /(\alpha+\gamma)]$ seems stronger ( $e$-fold change per $\sim 60 \mathrm{mV}$ between -130 and $-190 \mathrm{mV}$ or between -160 and $-220 \mathrm{mV}$; Figs. $2 C, 5 B)$. Moreover, the initial recovery rates in $150 \mathrm{~mm}$ external $\mathrm{K}^{+}$and in $150 \mathrm{mM}$ external $\mathrm{Na}^{+}$always differ by $\sim 4.5$ times at potentials between -70 and $-250 \mathrm{mV}$ (Fig. $4 C$ ), but the fast time constants of macroscopic recovery in these two conditions differ by only $\sim 2.3$ 
times (at -160 to $-190 \mathrm{mV}$, Figs. $2 C, 5 B$ ). With the foregoing equations these findings may imply that $\gamma$ is more voltagedependent than $\alpha$, and external $\mathrm{K}^{+}$probably accelerates only $\alpha$, but not $\gamma$.

\section{The route of recovery from inactivation for Shaker $\mathbf{K}^{+}$channels}

Unlike $\mathrm{Na}^{+}$channels, Shaker $\mathrm{K}^{+}$channels may take either the $\mathrm{OB}$ to $\mathrm{O}$ to $\mathrm{C}$ or $\mathrm{OB}$ to $\mathrm{CB}$ to $\mathrm{C}$ route to recover from inactivation. With reactions $\mathrm{O}$ to $\mathrm{OB}$ and $\mathrm{CB}$ to $\mathrm{OB}$ being negligible during recovery (see above), the preponderance of each route would be determined by the ratio between $\alpha$ and $\gamma$ in Figure 7. In $150 \mathrm{~mm}$ external $\mathrm{K}^{+}, 31-46 \%$ of recovery is via the $\mathrm{OB}$ to $\mathrm{CB}$ route at -130 to $-190 \mathrm{mV}$ (Fig. $2 E$ ). These are fairly close to the $\gamma /(\alpha+\gamma)$ ratios in Figure $7(29-43 \%)$ in the same conditions. In low external $\mathrm{K}^{+}, \alpha$ decreases, and the chance of getting into the OB to $\mathrm{CB}$ route is consequently higher. Figure $5 A$ indicates that the fast components comprise only $35-23 \%$ of total recovery at $-160 \mathrm{mV}$ to $-220 \mathrm{mV}$, or $65-77 \%$ of total recovery is via the $\mathrm{OB}$ to $\mathrm{CB}$ route. These are again close to the $\gamma /(\alpha+\gamma)$ ratios in Figure 7 (72-82\%). It is interesting to note that the $\gamma /(\alpha+\gamma)$ ratio is $\sim 50 \%$ at $-70 \mathrm{mV}$ in low external $\mathrm{K}^{+}$. Thus both recovery routes are probably similarly important in the physiological condition.

\section{Deactivation retards recovery from inactivation in Shaker $\mathrm{K}^{+}$channels: contrast with $\mathrm{Na}^{+}$channels}

Hyperpolarization apparently has two distinct effects on recovery of the inactivated Shaker channels. It hastens the initial recovery phase, presumably by facilitating the unblocking step $\mathrm{OB}$ to $\mathrm{O}$, yet retards the late recovery phase, presumably by forcing deactivation of the inactivated channels. A very interesting connotation from this finding is that the unblocking rate $\mathrm{CB}$ to $\mathrm{C}$ is significantly slower than $\mathrm{OB}$ to $\mathrm{O}$. The very slow components of recovery in Figures $5 A$ and 6 further suggest that the unblocking rate is even slower as the channel is deactivated more fully (very slow $\mathrm{C}^{\prime} \mathrm{B}$ to $\mathrm{C}^{\prime}$ rate). This is as if the inactivating particle is "locked" in the pore when the channel is forced to deactivate before the inactivating particle unblocks. The blocking of delayed rectifier $\mathrm{K}^{+}$channels in squid giant axon by tetraethylammonium (TEA) ion derivatives has been shown to be similar to $\mathrm{K}^{+}$channel inactivation in many aspects, including the findings that the unblocking of TEA derivatives is also four to five times faster when external $\mathrm{K}^{+}$is increased from 10 to $440 \mathrm{~mm}$ (Armstrong, 1971) and that TEA binding also strongly immobilizes the gating charges (Bezanilla et al., 1991; Perozo et al., 1993). In this light, it is interesting to note that the recovery from the block by TEA derivatives at $-100 \mathrm{mV}$ also shows a faster initial phase, yet a slower late phase, as compared with the recovery at $-60 \mathrm{mV}$ (Armstrong, 1971).

Such a lock-in effect of the inactivating particle in deactivated Shaker channels is in sharp contrast to the case in $\mathrm{Na}^{+}$channels, in which stronger hyperpolarization monotonously speeds up the whole course of recovery (Kuo and Bean, 1994). It seems that in $\mathrm{Na}^{+}$channels inactivation is coupled to activation, because the receptor conformation for the inactivating particle is "created" with channel activation and thus channel deactivation would "eject" the inactivating particle by destroying the receptor ("modulated receptor"), whereas the activation/deactivation processes in Shaker $\mathrm{K}^{+}$channels alter the "doorway" of the receptor ("guarded receptor"), with or without an as drastic change of the receptor conformation itself.

\section{Location of the external $\mathrm{K}^{+}$binding site of which the effective occupancy accelerates recovery from inactivation}

Consistent with previous reports (Demo and Yellen, 1991; Gomez-Lagunas and Armstrong, 1994), the initial recovery rates in $150 \mathrm{~mm}$ external $\mathrm{K}^{+}$are four to five times faster than those in $150 \mathrm{~mm}$ external $\mathrm{Na}^{+}$. The initial recovery rate may be expressed in terms of the occupancy of an enhancement site by external $\mathrm{K}^{+}$ (OP) as:

Initial recovery rate $=\mathrm{OP} \cdot$ enhanced unblocking rate

$$
+(1-\mathrm{OP}) \cdot \text { unenhanced unblocking rate. }
$$

Note that when external $\mathrm{K}^{+}$is exerting this recovery-enhancing effect the pore is blocked by the inactivating particle, so any $\mathrm{K}^{+}$ from the outside must go back to the outside. Thus OP will change with the membrane potential according to the electric distance of the site (Woodhull, 1973). Because different OP at different potentials will contribute to the overall change of initial recovery rate with voltage, the apparent voltage dependence of the initial recovery rate may be larger than the intrinsic voltage dependence of the unblocking rate (presumably the same in both enhanced and unenhanced conditions) itself.

The same initial recovery rates in $150-500 \mathrm{~mm}$ external $\mathrm{K}^{+}$ (Fig. 4C,D) suggest that the enhancement site is nearly fully occupied in $150 \mathrm{~mm}$ (or higher) external $\mathrm{K}^{+}$at -70 to $-250 \mathrm{mV}$ (see also Murrell-Lagnado and Aldrich, 1993). In other words, OP remains close to 1 and does not change significantly with membrane potential in these conditions. The observed voltage dependence of the initial recovery rates ( $e$-fold change per $\sim 90 \mathrm{mV}$ ) therefore must be fully ascribed to the intrinsic voltage dependence of the unblocking step. On the other hand, the enhancement site seems far from fully occupied in $150 \mathrm{~mm}$ external $\mathrm{Na}^{+}$, because the initial recovery rates here are four to five times slower. These initial recovery rates, however, still change $e$-fold per $90 \mathrm{mV}$, the intrinsic voltage dependence of the unblocking step. Thus OP does not change significantly from -70 to -250 $\mathrm{mV}$ even when the site is by far not saturated, indicating that the electric distance of the enhancement site is negligible from outside. This $\mathrm{K}^{+}$binding site thus may be located near the external entrance of the $\mathrm{K}^{+}$channel pore, just like the high-affinity $\mathrm{Ca}^{2+}$ binding sites in the L-type $\mathrm{Ca}^{2+}$ channel pore (Kuo and Hess, 1993) or even on the external surface of the Shaker $\mathrm{K}^{+}$channel. In either case the enhancement phenomenon possibly represents an allosteric rather than a direct "knock-off" effect, because the binding site for the inactivating particle presumably is located closer to the other end of the pore. Also, the existence of intrinsic voltage dependence of the unblocking step suggests that the inactivating particle is effectively charged and is bound to a receptor not located at electric distance $\sim 0$ from the internal pore mouth.

Gomez-Lagunas and Armstrong (1994) proposed that this recovery-enhancing $\mathrm{K}^{+}$binding site may be located deep in the pore (electric distance $>0.5$ from outside) because $\mathrm{Ca}^{2+}$, which blocks Shaker channels with an electric distance of 0.5 , cannot enhance recovery from inactivation, whereas $\mathrm{Cs}^{+}$, which blocks Shaker channels with an electric distance of 0.9 from outside, shows remarkable enhancement effect. However, $\mathrm{Ca}^{2+}$ might reach the enhancement site but could not bind to it well, and $\mathrm{Cs}^{+}$ might bind to a superficial site to enhance recovery before it binds to another, deeper site to block the pore. A superficial location of 
the enhancement site therefore is not incompatible with previous reports and seems to be the simplest way to explain the findings here.

\section{REFERENCES}

Armstrong CM (1971) Interaction of tetraethylammonium ion derivatives with the potassium channels of giant axons. J Gen Physiol 58:413-437.

Armstrong CM (1981) Sodium channels and gating currents. Physiol Rev 61:644-683.

Armstrong CM, Bezanilla F (1977) Inactivation of the sodium channel. II. Gating current experiments. J Gen Physiol 70:567-590.

Baukrowitz T, Yellen G (1995) Modulation of $\mathrm{K}^{+}$current by frequency and external $\left[\mathrm{K}^{+}\right]$: a tale of two inactivation mechanisms. Neuron 15:951-960.

Bezanilla F, Perozo E, Papazian DM, Stefani E (1991) Molecular basis of gating charge immobilization in Shaker potassium channels. Science 254:679-683.

Demo SD, Yellen G (1991) The inactivation gate of the Shaker potassium channel behaves like an open channel blocker. Neuron 7:743-753.

Gomez-Lagunas F, Armstrong CM (1994) The relation between ion permeation and recovery from inactivation of ShakerB $\mathrm{K}^{+}$channels. Biophys J 67:1806-1815.

Heginbotham L, MacKinnon R (1993) Conduction properties of the cloned Shaker $\mathrm{K}^{+}$channel. Biophys J 65:2089-2096.

Hille B (1992) Potassium channels and chloride channels. In: Ionic channels of excitable membranes, pp 116-121. Sunderland, MA: Sinauer.

Hoshi T, Zagotta WN, Aldrich RW (1990) Biophysical and molecular mechanisms of Shaker potassium channel inactivation. Science 250:533-538.

Hoshi T, Zagotta WN, Aldrich RW (1991) Two types of inactivation in
Shaker potassium channels: effects of alterations in the carboxyterminal region. Neuron 7:547-556.

Iverson LE, Rudy B (1990) The role of divergent amino and carboxyl domains on the inactivation properties of potassium channels derived from the shaker gene of Drosophila. J Neurosci 10:2903-2916.

Kamb A, Iverson LE, Tanouye MA (1987) Molecular characterization of shaker, a Drosophila gene that encodes a potassium channel. Cell 50:405-413.

Kuo C-C, Bean BP (1994) Sodium channels must deactivate to recover from inactivation. Neuron 12:819-829.

Kuo C-C, Hess P (1993) Characterization of the high-affinity $\mathrm{Ca}^{2+}$ binding sites in the L-type $\mathrm{Ca}^{2+}$ channel pore in rat phaeochromocytoma cells. J Physiol (Lond) 466:657-682.

MacKinnon R, Yellen G (1990) Mutations affecting TEA blockade and ion permeation in voltage-activated $\mathrm{K}^{+}$channels. Science 250:276-279.

Murrell-Lagnado RD, Aldrich RW (1993) Energetics of Shaker K channels blocked by inactivation peptides. J Gen Physiol 102:977-1003.

Perozo E, MacKinnon R, Bezanilla F, Stefani E (1993) Gating currents from a nonconducting mutant reveal open-closed conformations in Shaker $\mathrm{K}^{+}$channels. Neuron 11:353-358.

Rudy B (1988) Diversity and ubiquity of K channels. Neuroscience 25:729-749.

Ruppersberg JP, Frank R, Pongs O, Stocker M (1991) Cloned neuronal Ik(A) channels reopen during recovery from inactivation. Nature 353:657-660.

Woodhull AM (1973) Ionic blockage of $\mathrm{Na}^{+}$channels in nerve. J Gen Physiol 61:687-708.

Zagotta WN, Hoshi T, Aldrich RW (1990) Restoration of inactivation in mutant Shaker potassium channels by a peptide derived from ShB. Science 250:568-571. 